\title{
Multitechnique Assessment of the Interannual to Multidecadal Variability in Steric Sea Levels: A Comparative Analysis of Climate Mode Fingerprints $\mathscr{b}$
}

\author{
Julia Pfeffer, Paul Tregoning, Anthony Purcell, and Malcolm Sambridge \\ Research School of Earth Sciences, Australian National University, Canberra, Australian Capital Territory, Australia
}

(Manuscript received 15 October 2017, in final form 18 June 2018)

\begin{abstract}
Because of increased emissions of greenhouse gases oceans are warming, causing sea level to rise as the density of seawater falls. Predicting the rates of steric expansion is challenging because of the natural variability of the ocean and because observations are insufficient to adequately cover the ocean basins. Here, we investigate the ability of one ocean reanalysis, two objective analyses, and one combination of satellite geodetic measurements to accommodate data gaps and to reconstruct typical patterns of the steric sea level variability at interannual and multidecadal time scales. Six climate indices are used to identify robust features of the internal variability, using a Least Absolute Shrinkage and Selection Operator (LASSO) regression to select significant predictors of the steric variability. Spatially consistent fingerprints are revealed for all climate indices in the ocean reanalysis dataset, allowing the recovery of most of the steric variability observed in the tropical and North Pacific, as well as large fractions of the Atlantic and Indian Ocean signals. Robust climate mode fingerprints are also identified with high spatial resolution but limited temporal coverage in the geodetic observations. The objective analyses fail to detect many of the patterns expected from climate modes, especially before the Argo era. Climate indices constitute valuable yet underexploited tools to assess the performance of different techniques to reconstruct steric sea levels at interannual and multidecadal scales. Such progress will increase confidence in the historical reconstructions of steric sea levels, which is necessary to improve the closure of regional and global sea level budgets and to validate the predictions of climate models.
\end{abstract}

\section{Introduction}

Steric sea level changes are associated with ocean temperature and salinity changes, causing seawater to expand or contract as the density changes. According to the Intergovernmental Panel on Climate Change (IPCC) Fifth Assessment Report (e.g., Church et al. 2013a), ocean thermal expansion contributed about $40 \%$ of the global mean sea level rise observed from 1971 to 2010. On regional scales, steric sea levels can differ significantly from the global mean because of the combined effects of ocean circulation and wind stress transporting heat and salt across the ocean basins (e.g., Stammer et al. 2013). Comparisons of in situ measurements with satellite altimetry measurements revealed

\footnotetext{
Supplemental information related to this paper is available at the Journals Online website: https://doi.org/10.1175/JCLI-D-170679.s1.
}

Corresponding author: Julia Pfeffer, julia.pfeffer@anu.edu.au that most of the regional variability in sea surface heights has a steric origin (e.g., Cazenave and Llovel 2010; Piecuch and Ponte 2011; Meyssignac and Cazenave 2012). The regional sea level trends observed today are influenced by the natural variability of the ocean and climate and could have been very different in the past decades.

Unfortunately, the regional variability of steric sea level changes is extremely difficult to assess, especially during the twentieth century. Indeed, before the deployment of Argo floats in the 2000s (e.g., Roemmich et al. 2009), temperature and salinity measurements were mainly collected from merchant ships and research vessels, leaving large regions of the oceans unsampled (Fig. 1 in Abraham et al. 2013). Deep layers of the oceans were particularly poorly observed (e.g., Church et al. 2010) and salinity measurements were considerably less abundant than those of temperature (e.g., Levitus et al. 2005b).

To accommodate data gaps, objective analyses use statistical techniques to reconstruct of temperature and salinity changes in space and time (e.g., Boyer et al. 
2005; Cabanes et al. 2013; Good et al. 2013). Such analyses are generally limited in scope (few data before the 1990s and often restricted to depths above $700 \mathrm{~m}$ ) or resolution (data averaged over 3-5 years) to achieve statistically significant sampling, but constitute the most common practice for analyzing steric sea level changes (e.g., Ishii et al. 2006; Levitus et al. 2012).

Alternatively, ocean reanalyses rely on assimilation techniques to predict temperature and salinity changes across the world's ocean (e.g., Carton and Giese 2008; Balmaseda et al. 2013). The combination of in situ (and eventually satellite) measurements with ocean general circulation models (OGCM) allows reconstruction of historical observations with global coverage and monthly resolution since the beginning of the twentieth century (e.g., Yang et al. 2017). The absence of independent observations, however, makes reanalyzed signals difficult to assess, leaving intercomparisons as the main tools of quality control (e.g., Balmaseda et al. 2015).

Finally, since the launch of the Gravity Recovery and Climate Experiment (GRACE) satellite gravity mission in 2002, steric sea level changes can also be evaluated from sea level anomalies measured with satellite altimetry corrected for ocean mass changes (e.g., Chambers 2006). While only available for 15 years at present, satellite geodesy can be used to determine global (e.g., Llovel et al. 2014; Purkey et al. 2014) and regional (e.g., Volkov et al. 2017) changes in steric sea levels over the full ocean depth.

Evaluating the rates of ocean thermal expansion remains uncertain, as a large range of methods leads to a large range of values (Table 13.1 in Church et al. 2013a). While much attention has been paid to the reconstruction of the global mean (e.g., Ishii et al. 2006; Domingues et al. 2008; Levitus et al. 2012), discussing potential model biases (e.g., Gregory et al. 2013a; Church et al. 2013b), and imbalances in global mean sea level budgets (e.g., Gregory et al. 2013b; Hay et al. 2015), few studies have attempted to appraise the regional variability in steric sea levels. In a recent assessment report (Storto et al. 2017), ocean reanalyses were shown to display higher ensemble consistency than objective analyses, both at global and regional scales, especially in datasparse regions such as the Southern Ocean. Ocean reanalyses were also shown to be closer to geodetic estimates than objective analyses between 2003 and 2010 (Storto et al. 2017). These results remain limited by the small number of criteria (a seasonal cycle and a linear trend) and the relatively short time span (1993-2010) considered in the study. The assessment of the interannual to multidecadal variability in a representative ensemble of datasets would be particularly useful to understand the causes of regional variability in steric sea levels and to weigh the impact of the ocean and climate natural variability in global and regional sea level budgets (Church et al. 2013a).

Climate modes define typical patterns of the internal variability of the coupled atmosphere-ocean system shown to influence sea levels at interannual to multidecadal time scales for the Pacific, Indian, Atlantic, Arctic, and Southern Oceans (e.g., Han et al. 2017). Climate mode signals have been analyzed in various types of sea level observations, including satellite radar altimetry measurements (e.g., Zhang and Church 2012; Frankcombe et al. 2015), sea surface temperature measurements (e.g., Hamlington et al. 2012), climate model predictions (e.g., Roberts et al. 2016; Cheung et al. 2017), and tide gauge measurements (e.g., White et al. 2014). The earliest analysis suggesting that historical observations of steric sea levels were closely related to climate modes goes back to the late twentieth century (e.g., Stammer 1997). Since then, statistical decomposition of steric datasets with empirical orthogonal functions (EOF) has shown that the principal components (PC) of steric sea level variability are highly correlated with the El Niño-Southern Oscillation (ENSO), Pacific decadal oscillation (PDO; e.g., Levitus et al. 2005a), and North Atlantic Oscillation (NAO; e.g., Lombard et al. 2005). Regional analyses performed over the tropical (e.g., Meyssignac et al. 2012; Palanisamy et al. 2015) and Indo- (e.g., Nidheesh et al. 2013) Pacific confirmed that ENSO, PDO, and the Indian Ocean dipole (IOD) are major contributors to steric sea level variability.

This study proposes a new way to assess the performance of objective analyses, ocean reanalyses, and satellite geodesy at interannual and multidecadal time scales based on the analysis of six climate indices. Our objective is to isolate robust features of the internal variability in very different datasets and, based on that information, gauge the ability of different techniques to accommodate data gaps and reconstruct historical steric sea level changes. To this end, we analyzed the response of four steric datasets to six climate indices, using a Least Absolute Shrinkage and Selection Operator (LASSO) regression (e.g., Hastie et al. 2015) to perform variable selection. Ordinary least squares (OLS) regressions performed on observed (satellite altimetry) and predicted (climate models) sea level changes indeed showed strong aliasing between climate mode signals (e.g., Frankcombe et al. 2015), which can be mitigated with the application of bandpass filters aiming at separating high- and low-frequency contents of climate indices (e.g., Zhang and Church 2012). The LASSO is a regularization technique that performs variable selection 
TABLE 1. List of steric datasets used in this study.

\begin{tabular}{llclc}
\hline \multicolumn{1}{c}{ Type } & \multicolumn{1}{c}{ Source } & Time coverage & Depth coverage & Geographical coverage \\
\hline Objective analysis & EN4 & $1958-2015$ & Down to 2000 m & Global \\
Objective analysis & CORA5 & $1990-2015$ & Down to 2000 m & Global \\
Ocean reanalysis & ORAS4 & $1958-2015$ & Down to 5500 m & Global \\
Satellite geodesy & CMEMS-GSFC & $2003-15$ & Full ocean depth & Nearly global \\
\hline
\end{tabular}

through the penalization of the magnitude of the coefficients (e.g., Tibshirani 1996). In this study, we will investigate the potential of LASSO regressions to select the minimum set of appropriate climate indices for each geographical location within an ensemble of indices defined for different ocean basins.

First, the historical reconstructions of steric sea level changes derived from two objective analyses, one ocean reanalysis, and one combination of two geodetic datasets are presented. After the description of our climate mode analysis (based on a LASSO regression), we discuss the evolution of regional trends over three different time periods (1958-2015, 1990-2015, and 2003-15) characteristic of the four datasets considered. Finally, we show the fingerprints associated with the climate modes in each dataset, discuss their contribution to the total steric signal, and use that information to assess the ability of each technique to recover interannual and multidecadal signals. We found that climate indices are particularly useful to predict the steric signals over the tropical and North Pacific and that climate mode fingerprints are better recovered with the ocean reanalysis and geodetic datasets than with objective analyses.

\section{Steric datasets}

\section{a. Objective analyses}

Steric sea level anomalies $\eta_{S}$ are expressed as a function of density $\rho$ (e.g., Stammer 1997), which can be assumed to only depend on temperature $T$ and salinity $S$ (e.g., Antonov et al. 2002):

$\eta_{S}=-\int_{H}^{0} \frac{\rho-\rho_{0}}{\rho_{0}} d z=\int_{H}^{0}\left(-\frac{1}{\rho_{0}} \frac{\partial \rho}{\partial T} T^{\prime}-\frac{1}{\rho_{0}} \frac{\partial \rho}{\partial S} S^{\prime}\right) d z$,

where $H$ is the ocean depth, $\rho_{0}$ is a reference density profile, $T^{\prime}=T-T_{0}$ is the temperature anomaly relative to a reference temperature profile $T_{0}$, and $S^{\prime}=S-S_{0}$ is the salinity anomaly relative to a reference salinity profile $S_{0}$. In practice, $\eta_{S}$ is computed as the sum of thermosteric anomalies $\eta_{T S}$ due to temperature changes and halosteric anomalies $\eta_{H S}$ due to salinity changes, over $n$ ocean layers of width $h_{i}$ :

$$
\eta_{S}=\eta_{T S}+\eta_{H S}=\sum_{i=0}^{n} \alpha_{i} T_{i}^{\prime} h_{i}+\sum_{i=0}^{n}-\beta_{i} S_{i}^{s} h_{i}
$$

where $\alpha_{i}=\left(-1 / \rho_{0}\right) \partial \rho / \partial T$ and $\beta_{i}=\left(1 / \rho_{0}\right) \partial \rho / \partial S$ are the thermal expansion and saline contraction coefficients of the layer $i$ (McDougall and Barker 2011).

In situ temperature $T$ and salinity $S$ values come from two objective analyses: EN4 (Good et al. 2013) and Coriolis Ocean Dataset for Reanalysis (CORA5; Cabanes et al. 2013). These two products are based on the statistical analysis of temperature and salinity measurements from various sensors, including Argo floats, mechanical bathythermograph (MBT), expendable bathythermograph (XBT), conductivity-temperature-depth (CTD), and XCTD (expendable CTD) profilers, moorings, sea mammal data, and some drifting buoys. The EN4 analyses include a larger number of profiles during a longer time span (data updated each month since 1900) than CORA5 (data updated each year since 1990). The processing, corrections, quality control, and interpolation techniques applied to temperature and salinity data differ for the two products (Good et al. 2013; Cabanes et al. 2013). For example, the EN4 analyses give several choices of bias corrections for MBT and XBT profiles [here Gouretski and Reseghetti (2010) is used], while the bias correction in CORA5 is based on Hamon et al. (2012). The EN4 analyses are interpolated on 42 depth levels for the first $5500 \mathrm{~m}$ of the ocean with $1^{\circ}$ resolution, while CORA5 is interpolated on 152 depth levels for the first $2000 \mathrm{~m}$ of the ocean with $0.5^{\circ}$ resolution. In this study, EN4 data were extracted for the first $2000 \mathrm{~m}$ of the ocean, to avoid the interpretation of spurious signals at depth, and from January 1958 to December 2015 to match the Ocean Reanalysis System 4 (ORAS4) coverage. The CORA5 data, spanning from January 1990 to December 2015, are used in full and are linearly interpolated onto a regular $1^{\circ} \times 1^{\circ}$ grid to be compared with other datasets (Table 1 ).

Reference temperature $T_{0}$ and salinity $S_{0}$ profiles, used to compute temperature anomalies $T^{\prime}$ and salinity anomalies $S^{\prime}$ [Eqs. (1) and (2)], are the monthly climatological values taken from the World Ocean Atlas (WOA13V2; Locarnini et al. 2013; Zweng et al. 2013). Thermal expansion $\alpha$ and saline contraction $\beta$ coefficients are computed using Thermodynamic Equation Of 


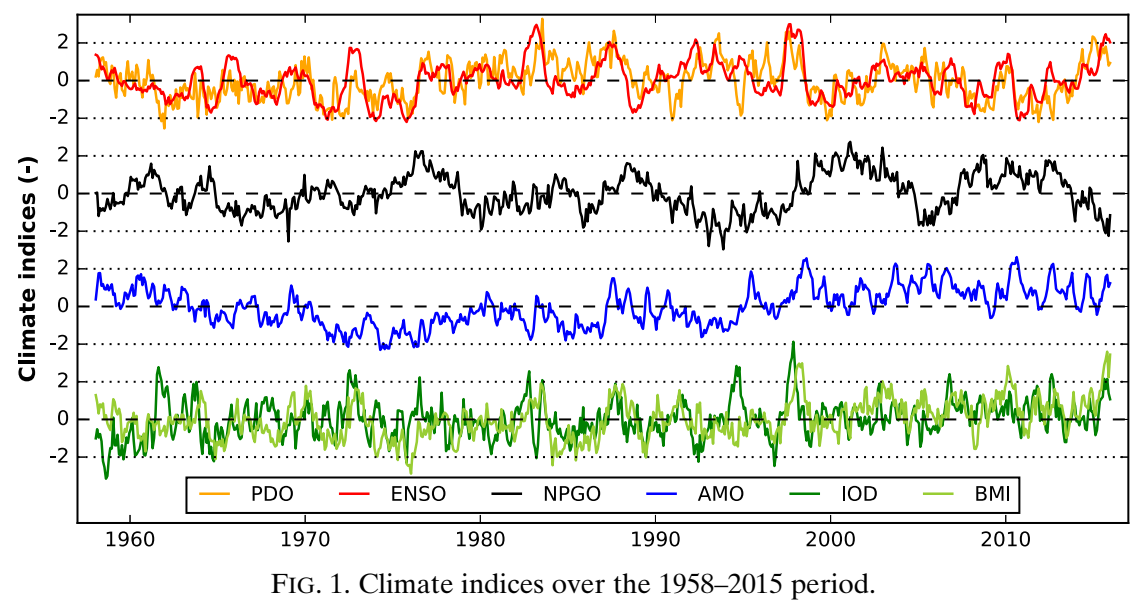

Seawater-2010 (TEOS-10; Millero 2010; McDougall and Barker 2011).

\section{b. Ocean reanalysis}

ORAS4 provides monthly estimates of the ocean state variables (including temperature and salinity) with a global coverage and a resolution of $1^{\circ}$ from 1958 to 2015 . Historical observations of the ocean and atmospheric fluxes are combined with NEMO (Madec 2008) predictions in the NEMO variational data assimilation system (NEMOVAR; Balmaseda et al. 2013). Forcing fields and observational datasets include temperature and salinity profiles from EN4 (Good et al. 2013), sea level anomalies from AVISO satellite altimetry distribution, as well as sea surface temperature and sea ice cover from ERA-40 (Uppala et al. 2005). Steric sea level anomalies are computed with the same method, the same climatological reference (WOA13V2) and the same equation of state (TEOS-10) as used in the objective analyses.

\section{c. Satellite geodesy}

Steric sea level changes can be expressed as the difference between total sea level anomalies and ocean mass changes and can therefore be estimated as the difference between satellite altimetry and GRACE measurements (e.g., Chambers 2006).

Here, sea level anomalies are estimated with the gridded multimission altimeter product, previously distributed by AVISO (Ssalto/Duacs sea level anomalies: DT-MSLA-H), now provided by the Copernicus Marine Environment Monitoring Service (CMEMS: SEALEVEL_GLO_PHY_L4_REP_OBSERVATIONS_ 008_047). Daily sea level anomalies are given from January 1993 to December 2015, with respect to a 20-yr mean, on a regular $0.25^{\circ} \times 0.25^{\circ}$ grid. To be consistent with GRACE data, sea level anomalies are averaged monthly, linearly interpolated to a $1^{\circ} \times 1^{\circ}$ grid, and corrected for glacial isostatic adjustment (GIA) using the ICE-5G (VM2) geoid correction computed by A et al. (2013). We use the same GIA model for altimetry (geoid correction) as for GRACE solutions (mass correction).

Ocean mass changes are estimated with the GRACE sea level anomaly (SLA) mascon solution (Luthcke et al. 2013) provided by the Goddard Space Flight Center (GSFC) from January 2003 to March 2016. The GSFC SLA mascon solution takes into account all necessary corrections to be consistent with satellite altimetry, including the global mean sea level pressure, GIA (A et al. 2013), and pole tides (Wahr et al. 2015). The GSFC SLA mascon solution, provided on a geodesic grid (respecting equal areas of approximately 1 square degree), is linearly interpolated onto a regular $1^{\circ} \times 1^{\circ}$ grid for each calendar month.

The geodetic steric anomalies, representative of the entire ocean width, are computed from January 2003 to December 2015 on a monthly basis and a regular $1^{\circ} \times$ $1^{\circ}$ grid (Table 1 ). The geographical coverage is nearly global, but altimetry values are missing at high latitudes because of ice coverage and the inclination of the satellite orbits.

\section{Description of the climate mode analysis}

\section{a. Choice of climate indices}

Climate indices have been developed to identify typical patterns of ocean and climate variability in all major ocean basins (e.g., Deser et al. 2010; Han et al. 2017). Here, six climate indices (Fig. 1) are used to represent the PDO, ENSO, North Pacific Gyre Oscillation (NPGO), Atlantic multidecadal oscillation (AMO), IOD, and Indian Ocean basin-wide mode (IOBM). The PDO expresses a decadal to multidecadal oscillation of the temperature in the North Pacific Ocean, along a 
TABLE 2. List of climate indices.

\begin{tabular}{lll}
\hline \hline Mode & \multicolumn{1}{c}{ Index definition } & \multicolumn{1}{c}{ Reference } \\
\hline PDO $^{\mathrm{a}}$ & First PC of SST anomalies over the North Pacific $\left(>20^{\circ} \mathrm{N}\right)$ & Mantua et al. (1997) \\
$\mathrm{ENSO}^{\mathrm{a}, \mathrm{b}}$ & First PC of six combined fields over the tropical Pacific $\left(30^{\circ} \mathrm{S}-30^{\circ} \mathrm{N}\right)$ & Wolter and Timlin (1993), (2011) \\
$\mathrm{NPGO}^{\mathrm{c}}$ & Second PC of SST anomalies over northeast Pacific $\left(180^{\circ}-110^{\circ} \mathrm{W}, 25^{\circ}-62^{\circ} \mathrm{N}\right)$ & Di Lorenzo et al. (2008) \\
$\mathrm{AMO}^{\mathrm{a}}$ & Detrended SST average over North Atlantic $\left(0^{\circ}-80^{\circ} \mathrm{N}\right)$ & Enfield et al. (2001) \\
$\mathrm{IOD}^{\mathrm{a}}$ & Difference of SST averages between west $\left(60^{\circ}-80^{\circ} \mathrm{E}\right)$ and east $\left(90^{\circ}-110^{\circ} \mathrm{E}\right)$ & Saji and Yamagata (2003) \\
& Indian Ocean & Yang et al. (2007) \\
$\mathrm{IOBM}^{\mathrm{d}}$ & First PC of SST anomalies over the Indian Ocean $\left(20^{\circ} \mathrm{S}-20^{\circ} \mathrm{N}, 40^{\circ}-110^{\circ} \mathrm{E}\right)$ & Y \\
\hline
\end{tabular}

${ }^{a}$ Data available on www.esrl.noaa.gov.

$\mathrm{b}$ The six combined fields are sea level pressure, zonal wind, meridional wind, SST, air temperature, cloud fraction.

${ }^{\mathrm{c}}$ Data available on www.ocean3d.org.

${ }^{\mathrm{d}}$ Computed with the HadSST3 (www.metoffice.gov.uk) dataset (Kennedy et al. 2011a,b).

typical northwest-southeast dipole (e.g., Mantua and Hare 2002). ENSO, strongly correlated with PDO, is a coupled atmosphere-ocean mode of interannual variability, expressed by periodic fluctuations of sea surface temperature (El Niño) and air pressure (Southern Oscillation), characterized by a west-east dipole across the tropical Pacific (e.g., Rasmusson and Wallace 1983). The NPGO reflects changes in the intensity of the central and eastern branches of the North Pacific Gyre circulations, forming a double gyre along the west coast of North America (e.g., Di Lorenzo et al. 2008). The AMO describes basin-wide changes in sea surface temperatures across the North Atlantic Ocean, with cool and warm phases that may last 20 to 40 years each (e.g., Enfield et al. 2001). The IOD is an oscillation of sea surface temperature in which the western Indian Ocean becomes alternately warmer and colder than the eastern part of the ocean (e.g., Saji et al. 1999). Finally, the IOBM is a periodic cooling and warming of the whole Indian Ocean, which is strongly related to ENSO events (e.g., Yang et al. 2007). Each climate mode is defined with a characteristic time series (or index) that is, in most cases, based on the analysis of sea surface temperature data (Table 2), except for the multivariate ENSO index (MEI), which merges six climate fields (Wolter 1987; Wolter and Timlin 1993).

\section{b. Removal of linear trends, annual cycles, and semiannual cycles}

The focus of this study is the interannual to multidecadal signals associated with climate modes. To isolate such variations, steric anomalies are first detrended and deseasoned. A linear trend, annual sinusoid, and semiannual sinusoid are simultaneously calculated by ordinary least squares adjustments and removed from each dataset. When the residuals of the regression exhibit significant serial correlation [tested with Ljung and Box (1978)], uncertainty values (given within one standard deviation) are adjusted for an effective sample size, accounting for a first-order autoregressive noise model (e.g., Santer et al. 2000; Pfeffer and Allemand 2016). More complex models might have to be considered to fully account for serial correlation, allowing more robust estimation of the uncertainties (e.g., Bos et al. 2014). This is unlikely to affect the first-order estimation of trends, annual cycles, and semiannual cycles and, therefore, would have little impact on the climate mode analyses performed on the residuals of the regression. Regional trends and uncertainty values are presented in Figs. 2 and 3. In the following, the detrended and deseasoned steric anomalies are referred as steric*.

\section{c. Regression of six climate indices with a LASSO constraint}

Our approach is based on a suite of time-series analyses, in which each singular grid element (a square degree) is treated independently. The steric* anomalies are inverted simultaneously for six climate indices (Table 2) in a LASSO regression (e.g., Tibshirani 1996; Hastie et al. 2015). The LASSO is a regularization technique, involving the addition of a constraint on the $l_{1}$ norm of the coefficients of the regression $\psi_{i}$, estimated by solving the minimization problem,

$$
\sum_{t=1}^{n}\left(y_{t}-\sum_{i=1}^{6} \psi_{i} \mathrm{CM}_{i, t}-\psi_{0}\right)^{2}+\lambda \sum_{i=1}^{6}\left|\psi_{i}\right|,
$$

where $y_{t}$ are the steric* anomalies, $\mathrm{CM}_{i, t}$ are the six climate indices, $\psi_{0}$ is a constant, and $\lambda$ is the penalty controlling the weight of the regularization. Because of the $l_{1}$ regularization, the coefficients $\psi_{i}$ shrink toward zero when they do not help to significantly reduce the residuals of the regression. The degree of shrinkage is controlled by the penalty $\lambda$, calculated so that it minimizes the prediction error plus one standard deviation of a fivefold cross validation (e.g., Arlot and Celisse 2010). Because the $l_{1}$ constraint will favor low-amplitude parameters, all indices are standardized $($ mean $=0$, 
a) EN4 : 1958 - 2015

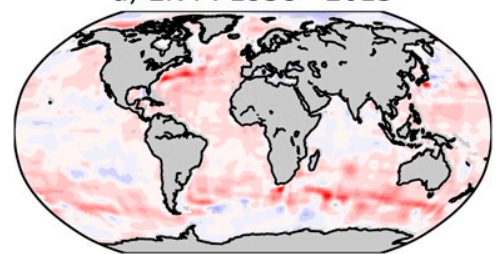

d) ORAS4 : 1958 - 2015

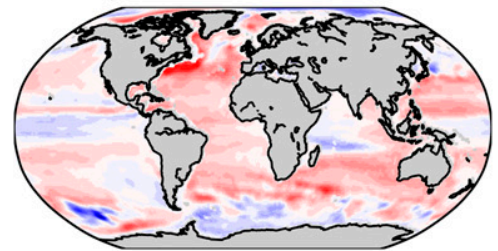

g) CORA5 : 1990 - 2015

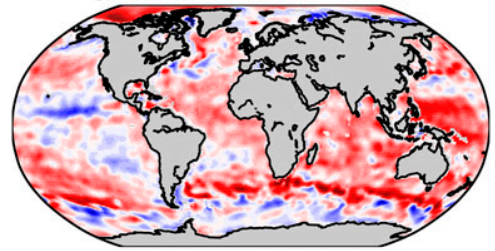

j) EN4 : 1958 - 2015

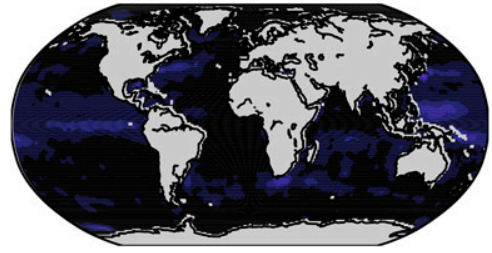

m) ORAS4 : 1958 - 2015

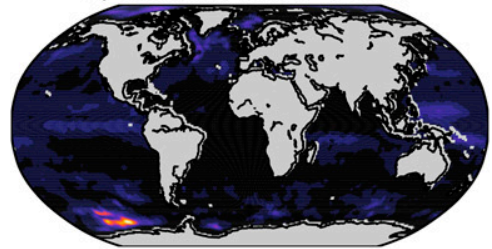

p) CORA5 : 1990 - 2015

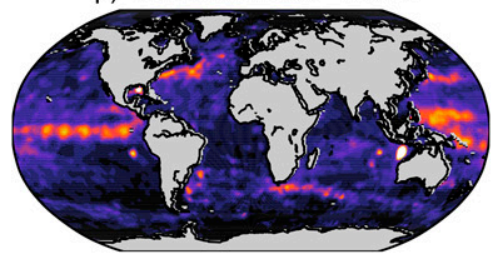

b) EN4 : 1990 - 2015

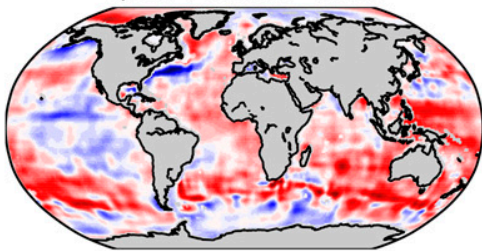

e) ORAS4 : 1990 - 2015

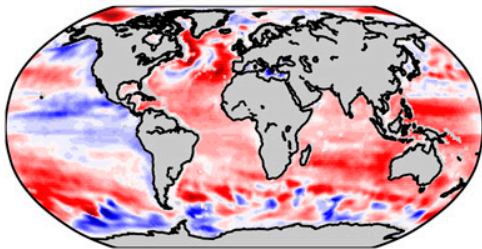

h) CORA5 : $2003-2015$

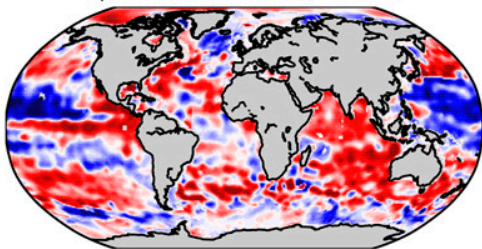

k) EN4 : 1990 - 2015

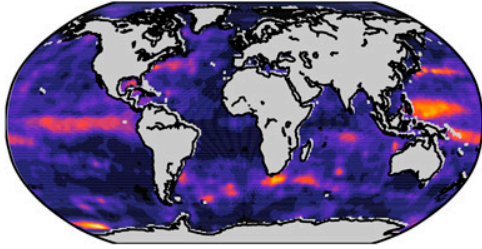

n) ORAS4 : 1990 - 2015

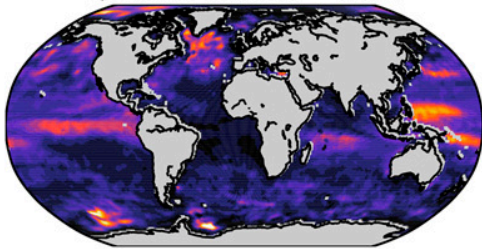

q) CORA5 : 2003 - 2015

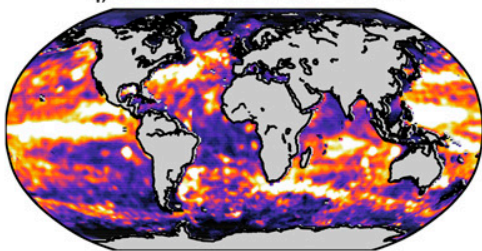

c) EN4 : 2003 - 2015

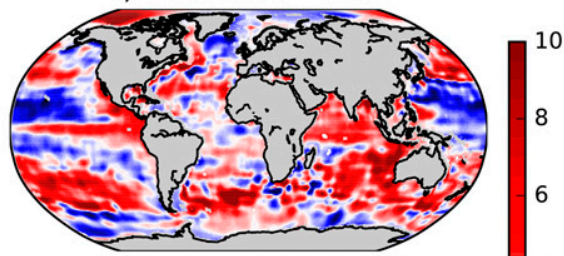

f) ORAS4 : 2003 - 2015

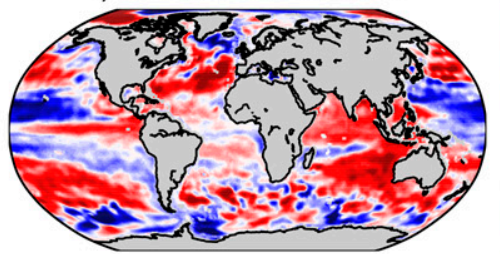

i) CMEMS - GSFC : 2003 - 2015

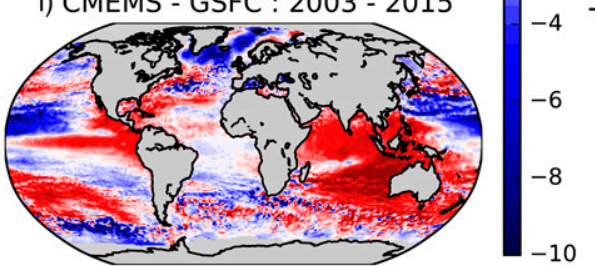

I) EN4 : 2003 - 2015

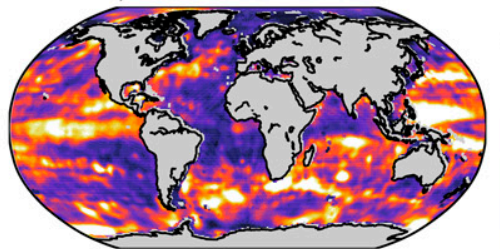

o) ORAS4 : 2003 - 2015

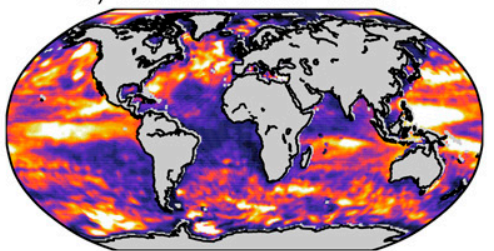

r) CMEMS - GSFC : 2003 - 2015

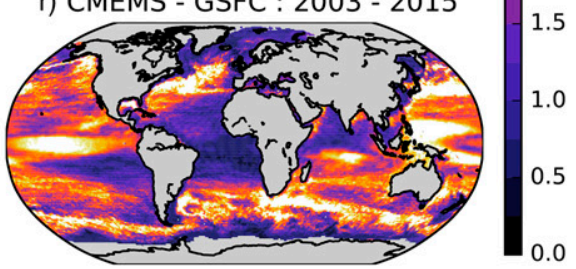

FIG. 2. (a)-(i) Linear trends and (j)-(r) trend uncertainties of steric anomalies evaluated with one ocean reanalysis (ORAS4: 1958-2015, 1990-2015, 2003-15), two objective analyses (EN4: 1958-2015, 1990-2015, 2003-15 and CORA5: 1990-2015, 2003-15), and one combination of geodetic measurements (CMEMS-GSFC: 2003-15).

standard deviation $=1$ ) over the time period considered in the analysis. Climate indices are not detrended or deseasoned.

Ideally, the LASSO will select relevant climate indices at each geographical location and lead to the generation of a simple, easily interpretable model with a minimal number of nonzero coefficients. However, the
LASSO will only be appropriate if the problem is sparse (i.e., steric* anomalies can be described with a minimal number of climate indices at each location). In our formulation, model sparseness has been encouraged by the simultaneous inversion of six climate indices, independently, at each geographical location. It is indeed highly unlikely for steric sea level changes to be influenced by 


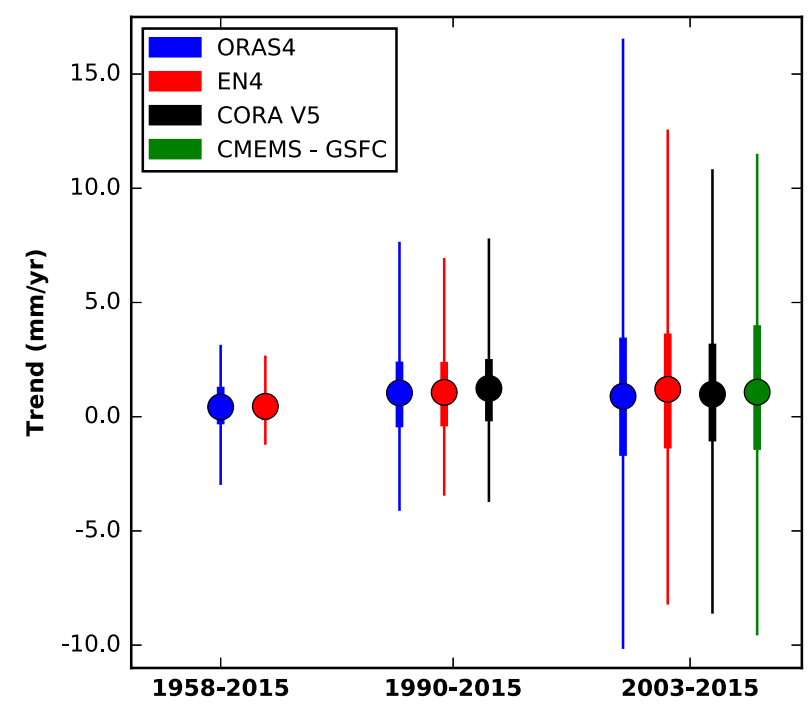

FIG. 3. Statistical distribution of regional trends in steric anomalies. Dots represent the mean, thick lines represent the first and third quartiles, and thin lines represent the 1st and 99th percentiles.

all six climate indices at the same place. Climate indices that are not significant will tend to have their coefficients reduced to zero by the LASSO. In the case of highly correlated variables (i.e., predictors), the solution might be unstable and the value of the coefficients will strongly depend on $\lambda$ (Hebiri and Lederer 2013). In this case, the value of the penalty should be adjusted according to a cross-validation process (Hebiri and Lederer 2013). The LASSO tends to generate regularized and parsimonious solutions that may not fully account for the complex interactions between climate indices. However, for many applications, the degree of complexity allowed in the regression model was appropriately tuned with crossvalidation procedures, even in the case of highly correlated predictors (e.g., Usai et al. 2009; Hammami et al. 2012; Toiviainen et al. 2014).

\section{Comparison of regional trends}

Regional trends in steric sea levels are strongly nonuniform (Fig. 2). The global average of steric trends ranges from 0.4 to $1.2 \mathrm{~mm} \mathrm{yr}^{-1}$ (Fig. 3) depending on the dataset and time period considered. The highest trends (from 5 to $15 \mathrm{~mm} \mathrm{yr}^{-1}$ ) are observed in the Arctic, Southern Ocean, southeast Indian Ocean, and tropical Pacific (Fig. 2). Strong local to regional variability is observed in complex ocean circulation regions, which leads to significant differences between the datasets across the northeast Atlantic and the Southern Ocean (Fig. 2). Significant decadal sea level variability (e.g., Calafat et al. 2012) and poor instrumental coverage (e.g., Abraham et al. 2013) may also explain the differences observed in the trend values for various historical reconstructions. Overall, the three datasets agree reasonably well when trends are compared over the same time period (Figs. 2 and 3). Major differences between the datasets are strongly dependent on their spatial resolution: Smaller-scale features can be detected with satellite geodesy; regional features are relatively patchy in objective analyses and more continuous in ocean reanalysis (Fig. 2).

The statistical distribution of regional trend values varies strongly with the time period considered, but is consistent from one dataset to another (Fig. 3). Over long time periods (1958-2015), steric sea level trends are relatively uniform (Fig. 2) and display and smaller range of variability (Fig. 3) and, by mathematical construction (e.g., Santer et al. 2000), a smaller uncertainty (Fig. 2) than those evaluated over shorter time periods. Higher extreme values (Fig. 3) and uncertainties (Fig. 2) are therefore found in steric trends when only considering 13 or 25 years of observation. The variability of steric sea levels is indeed impacted by natural oscillations acting on interannual to multidecadal time scales, which prevents the extrapolation of linear trends from short (one to several decades) to long (one century) time periods. The part of this variability associated with climate modes is assessed in the next section.

\section{Climate mode fingerprints}

Climate mode fingerprints are the solution coefficients $\psi_{i}$ of the LASSO regression presented in Eq. (3). There is no spatial constraint imposed in the analysis: Each time series of each grid point is treated independently. In spite of this, consistent spatial patterns are retrieved for each climate mode in steric sea level anomalies (Fig. 4). Before any detailed description of the results, it should be mentioned that the solutions are parsimonious ( $\psi_{i}=0$ in gray areas), revealing the ability of the LASSO to select one climate index over another, despite the relatively small number of predictors considered (only 6 climate indices) and their correlations (e.g., Deser et al. 2010; Han et al. 2017). The same analysis, performed with ordinary least squares regressions, provides noisier solutions that are much more difficult to interpret (see online supplementary material).

The steric* response to ENSO is clear and strong (up to $\pm 60 \mathrm{~mm}$ ), with the expected tropical Pacific dipole recovered in all datasets at all time scales (Figs. 4e-h). The influence of ENSO extends to the Indian Ocean (Figs. 4e-h), the South Pacific (Figs. 4e,f), and the Southern Ocean (Fig. 4e). Small-scale features, likely associated with turbulent eddies, are observed across the 


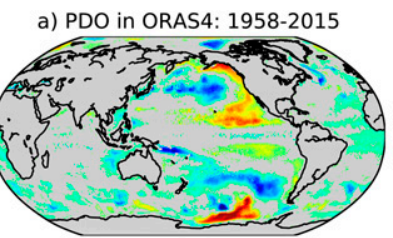

e) ENSO in ORAS4: 1958-2015

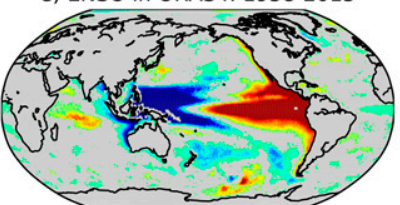

i) NPGO in ORAS4: 1958-2015

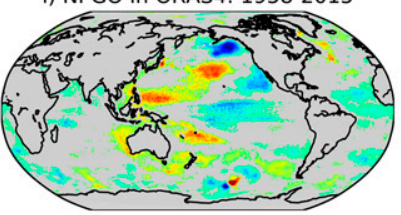

m) AMO in ORAS4: 1958-2015

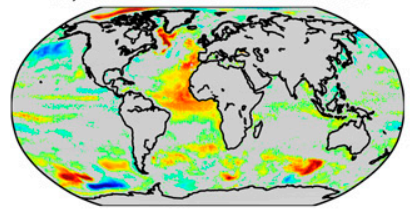

q) IOD in ORAS4: 1958-2015

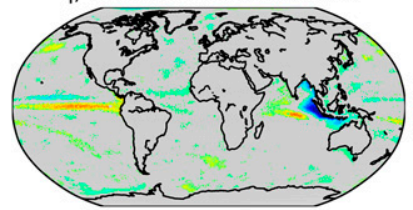

u) IOBM in ORAS4: $1958-2015$

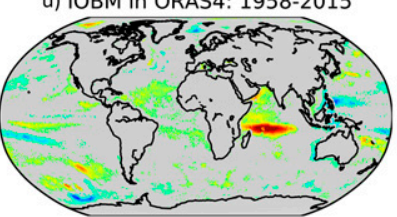

b) PDO in EN4: 1958-2015

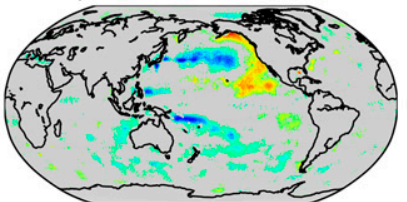

f) ENSO in EN4: 1958-2015

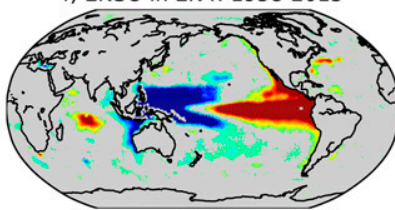

j) NPGO in EN4: 1958-2015

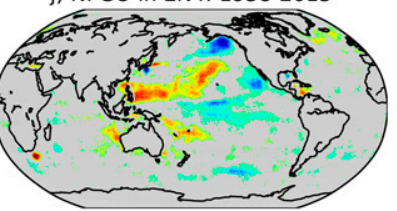

n) AMO in EN4: 1958-2015

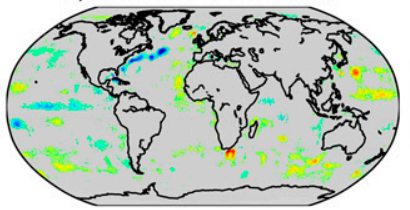

r) IOD in EN4: 1958-2015

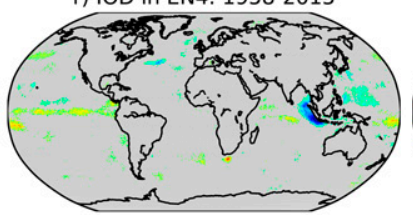

v) IOBM in EN4: 1958-2015 c) PDO in CORA5: 1990-2015

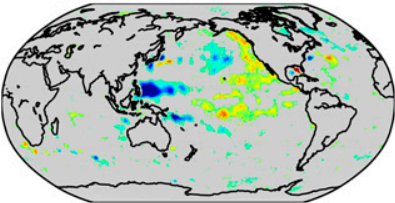

g) ENSO in CORA5: 1990-2015

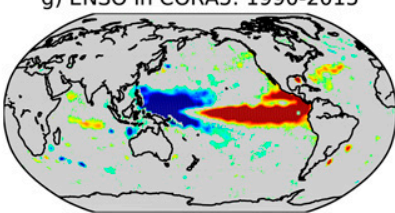

k) NPGO in CORA5: 1990-2015

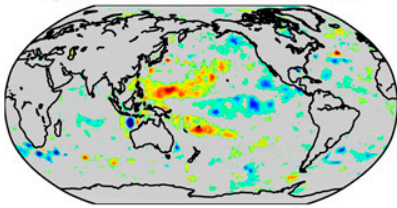

o) AMO in CORA5: 1990-2015

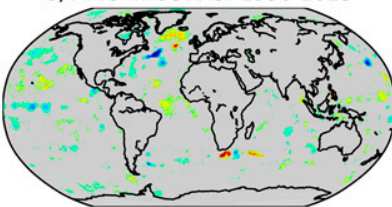

s) IOD in CORA5: 1990-2015

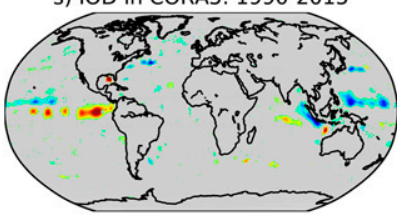

w) IOBM in CORA5: 1990-2015
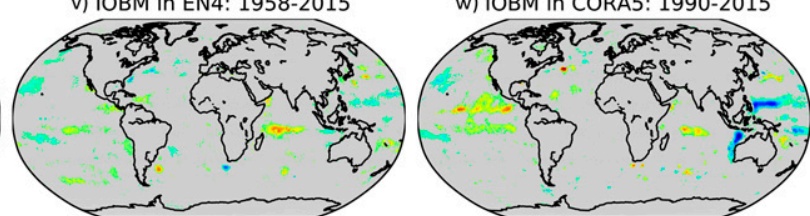

x) IOBM in CMEMS-GSFC: 2003-2015
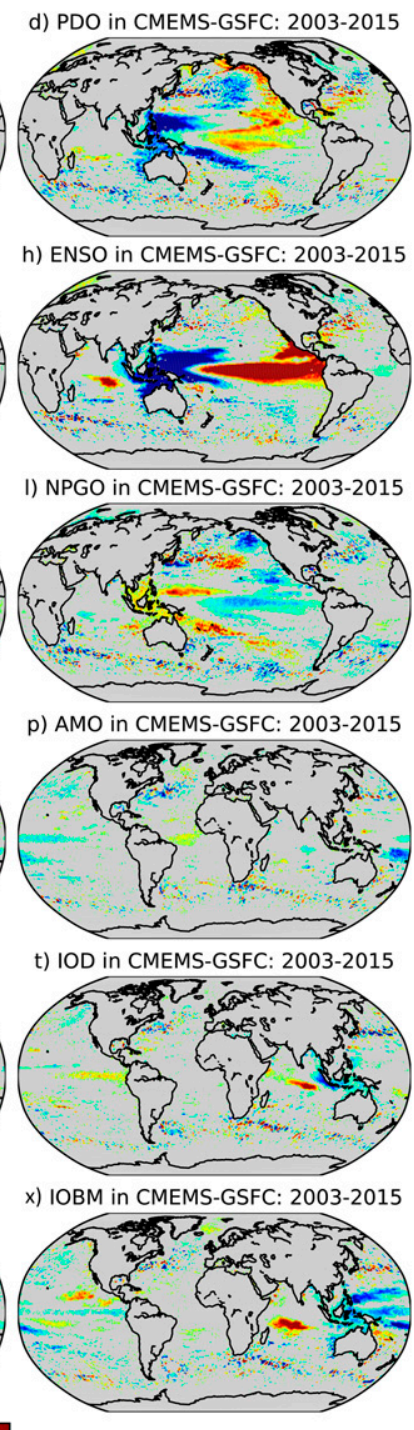

h) ENSO in CMEMS-GSFC: 2003-2015

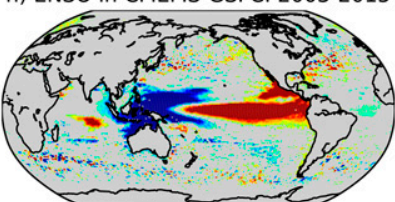

I) NPGO in CMEMS-GSFC: $2003-2015$

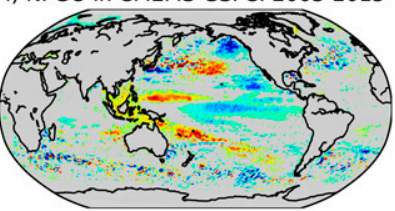

p) AMO in CMEMS-GSFC: $2003-2015$

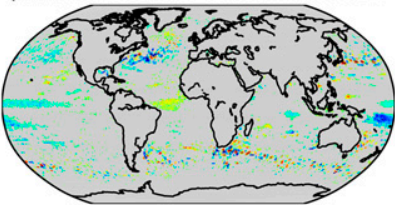

t) IOD in CMEMS-GSFC: $2003-2015$

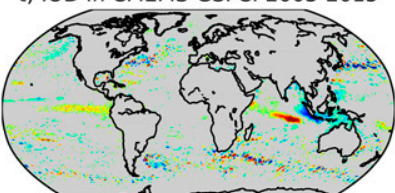

FIG. 4. Climate mode fingerprints in steric* anomalies evaluated with ocean reanalysis (ORAS4: 1958-2015), objective analyses (EN4: 1958-2015 and CORA5: 1990-2015), and geodesy (CMEMS-GSFC: 2003-15). The ENSO signal (about \pm 60 mm) extends beyond the color scale, chosen to represent all climate modes, including those with smaller amplitudes. Coefficients [ $\psi_{i}$ in Eq. (3)] equal to zero have been masked (in gray), as they do not contribute to the regression model.

Southern Ocean, Kuroshio region, and northeast Atlantic for all geodetic fingerprints (Fig. 4, last column), including ENSO.

Clear steric* responses to PDO (northwest-southeast dipole in the North Pacific) and NPGO (double gyre in the northeast Pacific) are observed in the ocean reanalysis (Figs. 4a,i) and geodetic (Figs. 4d,l) datasets, as well as in the EN4 objective analysis (Figs. 4b,j). The influences of PDO and NPGO on steric* sea levels seem to extend to the tropical and Southern Pacific in ORAS4, EN4, and CMEMS-GSFC fingerprints. In the
CORA5 objective analysis, PDO (Fig. 4c) and NPGO (Fig. 4k) patterns are observed with attenuated amplitudes and restricted extents.

A distinct response to AMO appears in the ocean reanalysis dataset (Fig. $4 \mathrm{~m}$ ), which benefits from a sufficient time coverage (1958-2015) to detect multidecadal oscillations. The AMO fingerprint consists of a positive anomaly over the Atlantic, extending from the Arctic to the southern tropics, with a notable absence of signal along the east coast of North America, probably masked by circulation processes. Some connections with 
AMO seem to be detected in the Arctic, Pacific, and Southern Ocean, which may potentially be artifacts of the regression (more details in the discussion). The AMO signal is not identified by any other dataset, including the objective analysis EN4 (Fig. 4n) spanning over the same time period as ORAS4 (1958-2015). Negative amplitudes $(-25 \mathrm{~mm}$ for EN4) are detected along the Gulf Stream that might be related to AMO, but do not strongly emerge from the solution noise (Figs. 4n-p).

The steric* responses to IOD and IOBM have less amplitude in all datasets (Figs. 4q-x). A west-east dipole can be observed across the Indian Ocean in reanalyzed (Fig. 4q) and geodetic (Fig. 4t) fingerprints. The dipole is, however, smaller than typical IOD patterns (e.g., Saji et al. 1999) observed in sea surface temperature (SST) anomalies (Table 2), and is confined to the east of the basin. For the IOBM, positive anomalies (Figs. 4u,x) are observed in the west of the Indian Ocean, which are also smaller than typical IOBM fingerprints (e.g., Yang et al. 2007) observed in SST (Table 2) data. Connections with the tropical and South Pacific are observed for both modes in ocean reanalysis (Figs. $4 \mathrm{~m}, \mathrm{p}$ ) and geodetic (Figs. 4o,r) datasets. There is no evident response to IOD or IOBM in the objective analyses (Figs. $4 \mathrm{r}, \mathrm{s}, \mathrm{v}, \mathrm{w}$ ) data. Though the positive part of the Indian dipole lies undetected in both datasets, the negative pole is larger in EN4 (Fig. 4r) than CORA5 (Fig. 4s). A positive anomaly of low amplitude (less than $10 \mathrm{~mm}$ ) and small geographical coverage (Figs. 4v,w) is detected in the west of the Indian Ocean for the IOBM, but it is not significantly different from the solution noise.

\section{Discussion}

A large part of the steric* variability observed with ocean reanalysis, objective analyses, and satellite geodesy can be predicted by the combination of six climate indices presented in Fig. 1 and Table 2. We evaluate the contribution of climate modes to the observed steric* signal with the coefficient of determination $R^{2}$, interpreted as the ratio of predicted to observed variance (Fig. 5, first column). In the tropical Pacific $\left(\sim 20^{\circ} \mathrm{S}-\right.$ $20^{\circ} \mathrm{N}$ ), the major part (up to $80 \%$ in the geodetic dataset) of the steric* variance can be predicted by a combination of climate modes, including, in particular, ENSO. Along the North American Pacific coastline, up to $60 \%$ of the steric* variance can be predicted by a combination of PDO and NPGO indices in the geodetic and ocean reanalysis datasets. In the central part $\left(\sim 5^{\circ}-10^{\circ} \mathrm{S}\right)$ and along the east coast $\left(\sim 100^{\circ}-115^{\circ} \mathrm{E}\right)$ of the Indian Ocean, up to $45 \%$ of the geodetic and reanalyzed steric* variance can be predicted by a combination of climate indices (IOD, IOBM, and ENSO). Finally, in a large part of the North Atlantic (including the Labrador Sea and the southeast quadrant), up to $30 \%$ of the reanalyzed steric* variance is predicted by AMO.

The recovery of the complete steric signal is significantly improved when climate modes are combined with a linear trend, an annual sinusoid, and a semiannual sinusoid, with $R^{2}$ values exceeding 0.5 over large regions of the world's oceans (Fig. 5, second column). In particular, high $R^{2}$ values are reached for the geodetic dataset (Fig. 5k), largely because of high amplitudes in the annual and semiannual sinusoids. Annual and semiannual signals are much smaller in the ocean reanalysis and objective analysis datasets, in which steric anomalies are computed with respect to the climatology. Overall, the results of our climate mode analysis (six climate indices and six fingerprints) can be used in several regions of the world (tropical Pacific, eastern Pacific, and large parts of the Atlantic and Indian Oceans) to predict the steric variability with a limited number of parameters, with about $60 \%-90 \%$ of signal recovered in recent years (2003-15; Fig. 5k) and $50 \%-75 \%$ of the signal recovered over longer time scales (1958-2015) when using ocean reanalysis (Fig. 5b).

Climate indices cannot fully predict the steric signals (Fig. 5, last column), as other relevant processes contribute to the ocean variability. Complex circulation processes occur, for example, in the Southern Ocean, northeast Atlantic, and Kuroshio region. In these regions, the climate indices that we have used are unable to explain the steric signal (low $R^{2}$ and high RMSE values in Fig. 5). Particularly low RMSE values are seen in the ocean reanalysis, which may be due to the underestimation of transport energy in these regions (Balmaseda et al. 2013). Globally averaged, climate indices can predict $11 \%$ of the ocean reanalysis, $5 \%$ and $4 \%$ of the objective analyses (EN4 and CORA5, respectively), and $10 \%$ of the geodetic steric* variance. When a linear trend, an annual sinusoid, and a semiannual sinusoid are added to the climate indices, $37 \%$ of the steric signal can be predicted in ocean reanalysis, $26 \%$ and $28 \%$ in objective analyses (EN4 and CORA5, respectively), and $39 \%$ in satellite geodesy. Other climate indices representing the North Atlantic Oscillation (NAO), Arctic Oscillation (AO), and Antarctic Oscillation (AAO) have been considered to complete the model, but were found to be inefficient (improvement of $R^{2}$ values smaller than 0.03 locally) to predict interannual or decadal variations in our steric* reconstructions.

Our analysis reveals climate mode fingerprints synchronous with climate indices, providing typical series of events and oscillations, identified point by point in 
a) CM in ORAS4 ${ }^{*}: 1958-2015$

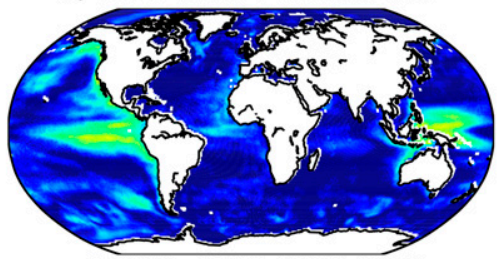

d) $\mathrm{CM}$ in EN4 ${ }^{*}: 1958-2015$

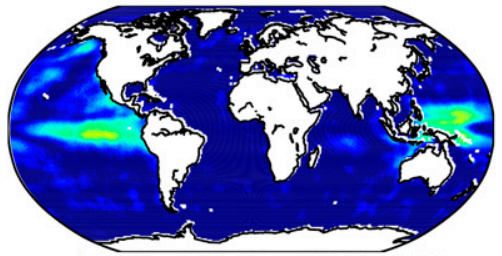

g) CM in CORA5 $*: 1990-2015$

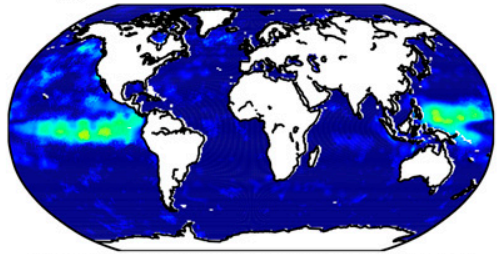

j) CM in CMEMS-GSFC * : 2003-2015

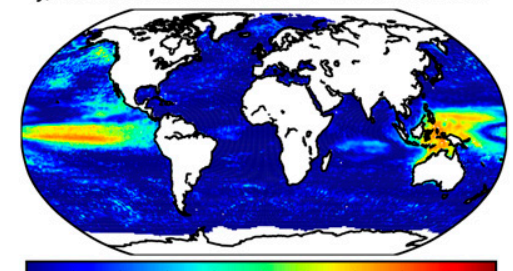

$\begin{array}{llllllllllll}0.0 & 0.1 & 0.2 & 0.3 & 0.4 & 0.5 & 0.6 & 0.7 & 0.8 & 0.9 & 1.0\end{array}$ $\mathrm{R}^{2}(-)$ b) Full model in ORAS4: 1958-2015

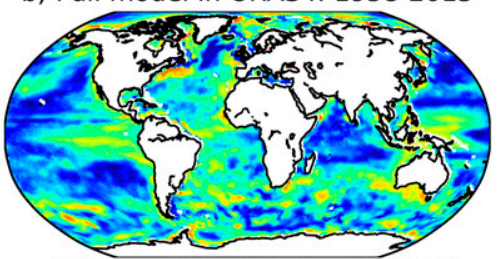

e) Full model in EN4: 1958-2015

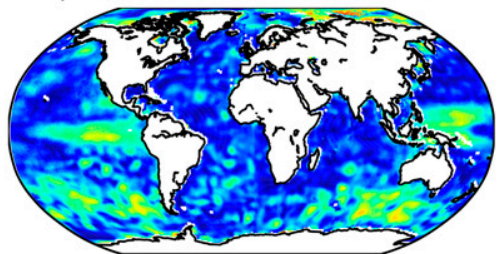

h) Full model in CORA5: 1990-2015

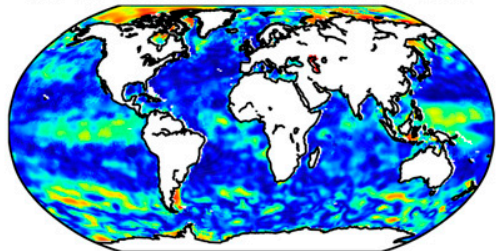

k) Full model in CMEMS-GSFC: 2003-2015

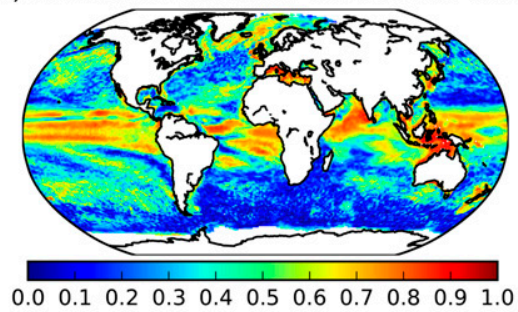

$\mathrm{R}^{2}(-)$ c) ORAS4 residuals: $1958-2015$

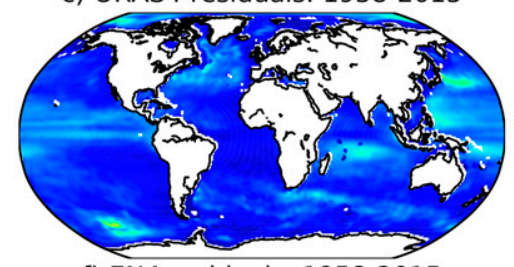

f) EN4 residuals: 1958-2015

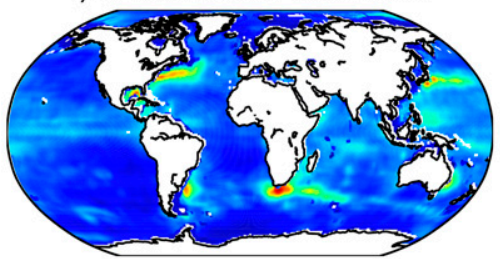

i) CORA5 residuals: 1990-2015

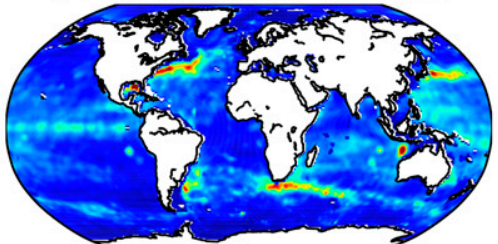

I) CMEMS-GSFC residuals: 2003-2015

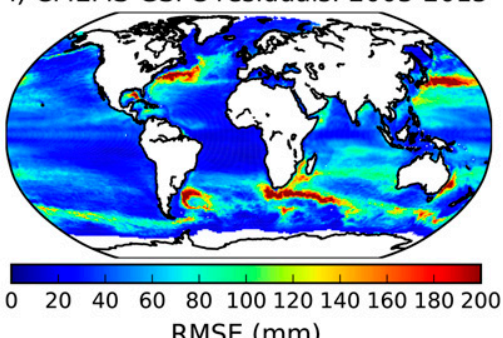

FIG. 5. Contribution of predicted signals to historical steric reconstructions derived from an ocean reanalysis (ORAS4: 1958-2015), two objective analyses (EN4: 1958-2015 and CORA5: 1990-2015) and one combination of satellite geodetic measurements (CMEMS-GSFC: 2003-15). (a),(d),(g),(j) The $R^{2}$ values between the climate modes predictions and steric* anomalies. (b),(e),(h),(k) The $R^{2}$ values between the total predicted steric anomalies (including a linear trend, an annual sinusoid, a semiannual sinusoid, and six climate indices) and the historical reconstructions. (c),(f),(i),(l) The RMSE values associated with the steric residuals (i.e., difference between the historical reconstructions and total predicted anomalies).

steric* sea levels with a LASSO regression. Sea level changes occur, however, on a wide range of temporal scales (e.g., Carton and Giese 2008), so that aliasing of temporal signals (e.g., Ray 1998) should be expected in steric* time series (e.g., Stammer 1997). Climate indices reflect to some extent this issue, as long-term SST anomalies result in large part from the stochastic response of the ocean surface to the excitation of the atmosphere at high frequencies (e.g., Frankignoul and Hasselmann 1977). Besides, climate modes are intrinsically coupled with one with another. The PDO includes, for example, a reddened response to ENSO (e.g., Newman et al. 2016). Similarly, IOD (e.g., Ashok et al. 2003) and IOBM (e.g., Yang et al. 2007), while constituting inherent modes of variability of the Indian Ocean, have been shown to interact with ENSO through the atmospheric bridge. The reemergence of climate mode signals (e.g., Nidheesh et al. 2017) through atmospheric or oceanic teleconnections patterns, that are not already included in the six climate indices considered here (Table 2), cannot be detected with our approach, which does not include a time lag.

The LASSO aims to find the minimal set of climate indices explaining the typical succession of events and oscillations constituting each time series. Because of temporal aliasing, some of the signals predicted with climate modes may be artifacts of the regression. For example, the AMO index is the only one to display multidecadal oscillations. Long-term oscillations present in steric* time series may overfit this index in order to explain some of the variance. Also, complex circulation processes are likely to generate a high level of noise 
and variability in the steric sea levels observed over the Southern Ocean, northeast Atlantic, and Kuroshio region, so that observed steric anomalies may be aliased with climate modes in the regression process. This may explain the small-scale variability observed in geodetic fingerprints (Fig. 4, last column) in complex ocean circulation regions (Southern Ocean, Kuroshio, and Gulf Stream regions). Overfitting issues are reduced by the LASSO constraint, which only allows solution coefficients $\left[\psi_{i}\right.$ in Eq. (3)] to be different from zero if they significantly minimize the residuals.

On the other hand, an overestimation of the LASSO constraint would lead to the underestimation of the parameters $\left[\psi_{i}\right.$ in Eq. (3)] of the regression, which would result in a shrinkage of climate mode fingerprints. Such scenario may be observed in the northeast Atlantic, where a high level of noise is expected because of the oceanic circulation, which may mask the AMO signal retrieved in the ocean reanalysis dataset (Fig. $4 \mathrm{~m}$ ). This may also explain why the IOD and IOBM fingerprints are smaller than typical SST patterns observed for these two modes (e.g., Saji et al. 1999; Yang et al. 2007). The cross-validation process ensures the balance between the excess of noise (low LASSO constraint) and the absence of solution (high LASSO constraint). Overall, the climate mode fingerprints retrieved with steric* datasets are consistent with typical signatures observed in SST (e.g., Deser et al. 2010) and sea surface heights (e.g., Han et al. 2017).

If many common characteristics are shared among the four datasets compared, our analysis points out the abilities of each technique to detect interannual to multidecadal signals. Ocean reanalysis performs remarkably well, as relevant fingerprints are recovered for each climate mode with relatively low noise. In spite of the short (13 years) record available, satellite geodesy also allows us to recover many relevant features of the steric* variability for most of the climate modes. The climate mode fingerprints retrieved in the geodetic dataset exhibit, however, a rather high level of noise in the Southern Ocean, Gulf Stream, and Kuroshio regions, appearing as small-scale signals likely associated with ocean circulation, such as eddies. The difficulty of isolating climate mode signals in objective analyses is presumably related to the sparsity of measurements. Among the two objective analyses considered, the EN4 dataset was better able to recover the climate mode signals associated with the PDO and NPGO, probably because of the inclusion of a larger number of temperature and salinity profiles. Neither EN4 nor CORA5 could detect the typical patterns expected from the AMO, IOD, or IOBM. The performance of objective analyses is noticeably improved in recent years (2003-15), which benefited from increased data coverage, with the detection of stronger PDO, NPGO, IOD, and IOBM fingerprints (see appendix, Fig. A1).

We acknowledge that only four products are considered in this study and that different results may be obtained with other datasets (Storto et al. 2017). However, because the datasets considered here are representative of the three techniques available to reconstruct steric signals, the main conclusions reported here should remain valid in the general case. Different datasets should be included in future assessments of the interannual to multidecadal steric variability to generalize these findings.

\section{Conclusions}

The regional variability of steric sea levels is strongly influenced by climate modes oscillating from interannual to multidecadal time scales. A combination of six climate indices (PDO, ENSO, NPGO, AMO, IOD, and IOBM) can explain most of the detrended and deseasoned steric variance observed across the tropical and North Pacific (especially along the coast with North America), and large parts of the variance in the Atlantic and Indian Oceans. The comparison of four steric datasets reveals that the ocean reanalysis dataset outperforms the other three, as it is the only one able to predict the signals associated with climate modes on multidecadal time scales. Geodetic techniques offer promising solutions to reveal the regional variability of steric sea levels but on shorter time scales (less than 15 years). The two objective analyses, on the other hand, struggle to recover the variability associated with climate modes other than ENSO (which is the only mode recovered with CORA5), PDO, and NPGO (which are the three modes recovered with EN4). The objective analyses datasets perform better after 2003, likely because of the deployment of Argo floats.

While opening new possibilities to investigate the interannual to multidecadal variability in steric sea levels, our approach has two main limitations. First, only six climate indices and four steric products are considered in our analysis. Future studies assessing the steric variability related to climate modes should include different datasets and climate indices to generalize the findings reported here. Besides, the interpretation of the steric variability is limited to the combination of a linear trend, an annual sinusoid, a semiannual sinusoid, and six climate indices. Aliasing of climate mode signals is neglected with our approach, which does not include a time lag. Besides, other sources of variability could be considered to explain the steric signal, especially across complex ocean circulation regions such as the Southern Ocean, Gulf Stream, and Kuroshio regions. 


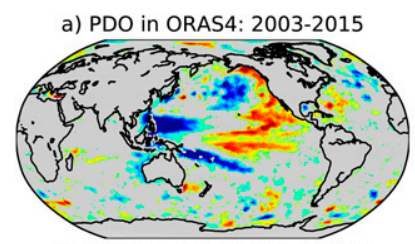

e) ENSO in ORAS4: 2003-2015

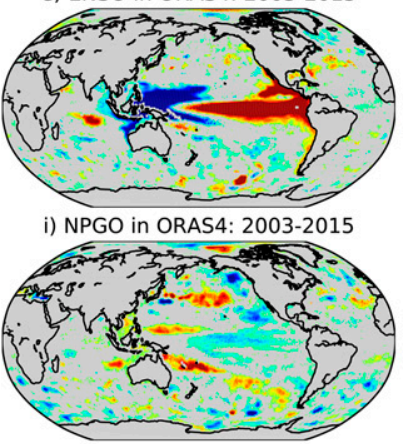

m) AMO in ORAS4: 2003-2015

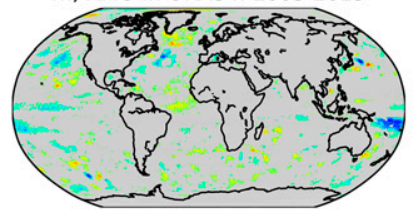

q) IOD in ORAS4: 2003-2015

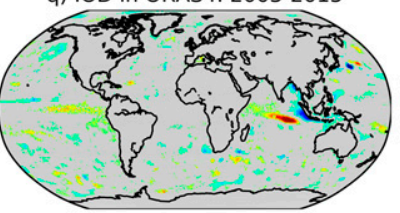

u) IOBM in ORAS4: 2003-2015

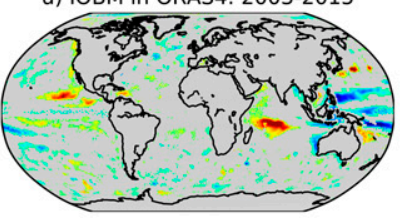

b) PDO in EN4: 2003-2015

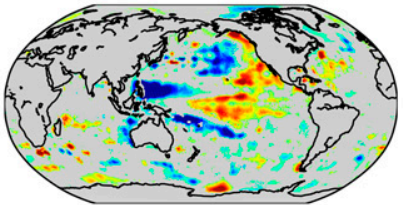

f) ENSO in EN4: 2003-2015

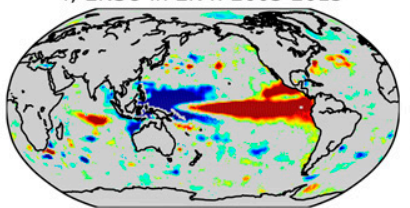

j) NPGO in EN4: 2003-2015

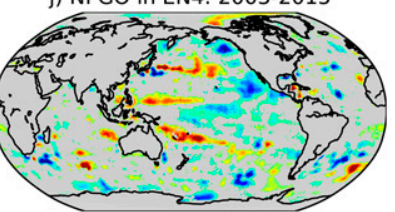

n) AMO in EN4: 2003-2015

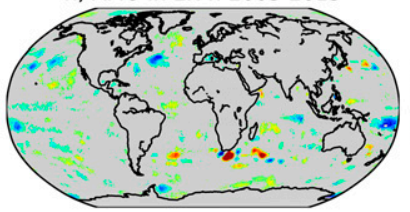

r) IOD in EN4: 2003-2015

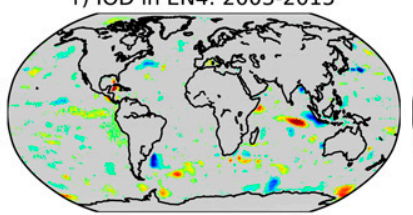

v) IOBM in EN4: 2003-2015

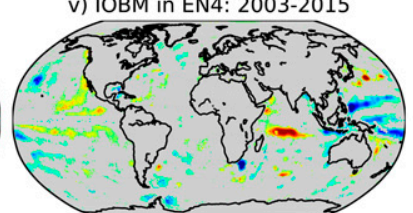

c) PDO in CORA5: 2003-2015

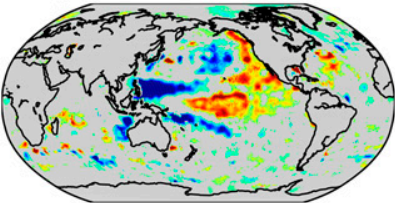

g) ENSO in CORA5: 2003-2015

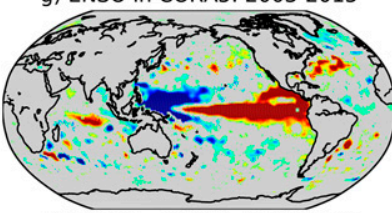

k) NPGO in CORA5: 2003-2015

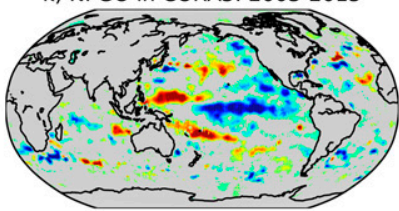

o) AMO in CORA5: 2003-2015

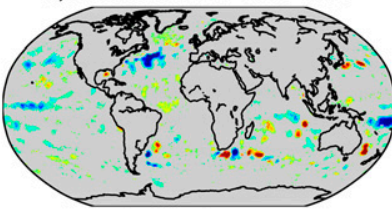

s) IOD in CORA5: 2003-2015

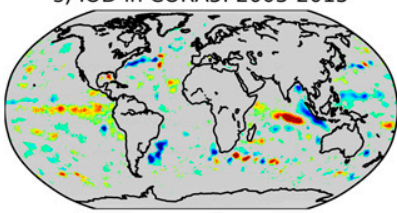

w) IOBM in CORA5: 2003-2015

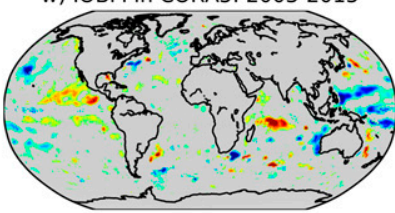

d) PDO in CMEMS-GSFC: 2003-2015

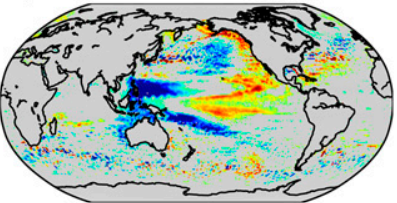

h) ENSO in CMEMS-GSFC: 2003-2015

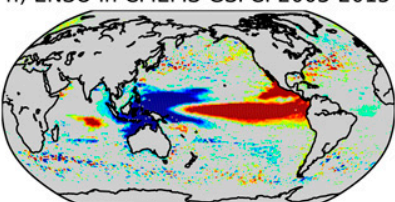

I) NPGO in CMEMS-GSFC: 2003-2015

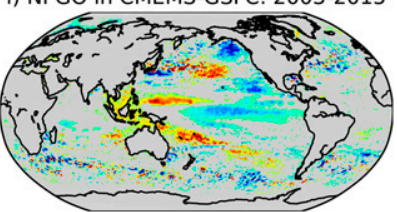

p) AMO in CMEMS-GSFC: 2003-2015

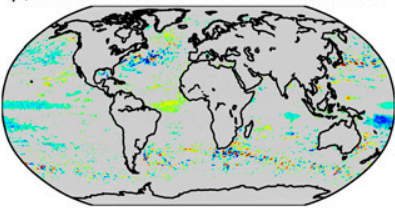

t) IOD in CMEMS-GSFC: $2003-2015$

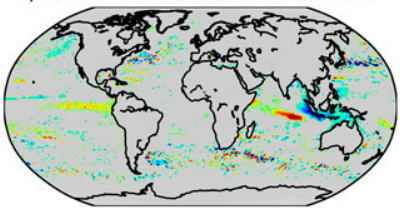

x) IOBM in CMEMS-GSFC: 2003-2015

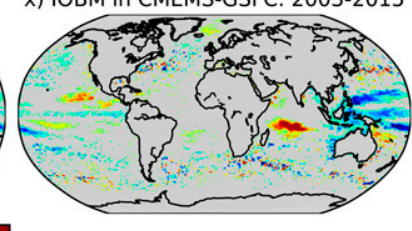

FIG. A1. Comparison of climate mode fingerprints in one ocean reanalysis, two objective analyses, and one combination of satellite geodetic observations over recent years (2003-15).

The approach presented in this study can, however, be used to identify robust features of the steric variability at interannual and multidecadal time scales with a combination of only six climate indices and six climate mode fingerprints. Such information will make it possible to partially reconstruct steric signals over time spans as long as the climate indices themselves, which will be particularly valuable for the interpretation of long tide gauge records. Climate indices provide useful criteria to assess the efficiency of ocean reanalyses, objective analyses, and satellite geodesy to reconstruct the interannual to multidecadal changes in steric sea levels associated with the natural variability of ocean and climate. Our approach is based on a simple parametric model that can be easily adapted to different datasets. Such progress is important to increase confidence in the historical reconstructions of steric sea levels and to guide the selection of steric products used to compute sea level budgets and validate climate model predictions.

Acknowledgments. We thank three anonymous reviewers for their helpful comments. The research was funded by the Australian Research Council (Discovery Project: 160100070). 


\section{APPENDIX}

\section{Comparison of Climate Mode Fingerprints from 2003 to 2015}

Figure A1 shows fingerprints recovered from one ocean reanalysis (ORAS4), two objective analyses (EN4 and CORA5), and one combination of satellite geodetic observations (CMEMS-GSFC) over the same time pe$\operatorname{riod}(2003-15)$.

\section{REFERENCES}

A, G., J. Wahr, and S. Zhong, 2013: Computations of the viscoelastic response of a 3-D compressible Earth to surface loading: An application to glacial isostatic adjustment in Antarctica and Canada. Geophys. J. Int., 192, 557-572, https://doi.org/ 10.1093/gji/ggs030.

Abraham, J. P., and Coauthors, 2013: A review of global ocean temperature observations: Implications for ocean heat content estimates and climate change. Rev. Geophys., 51, 450-483, https://doi.org/10.1002/rog.20022.

Antonov, J. I., S. Levitus, and T. P. Boyer, 2002: Steric sea level variations during 1957-1994: Importance of salinity. J. Geophys. Res., 107, 8013, https://doi.org/10.1029/ 2001JC000964.

Arlot, S., and A. Celisse, 2010: A survey of cross-validation procedures for model selection. Stat. Surv., 4, 40-79, https://doi.org/ 10.1214/09-SS054.

Ashok, K., Z. Guan, and T. Yamagata, 2003: A look at the relationship between the ENSO and the Indian Ocean dipole. J. Meteor. Soc. Japan, 81, 41-56, https://doi.org/10.2151/ jmsj.81.41.

Balmaseda, M. A., K. Mogensen, and A. T. Weaver, 2013: Evaluation of the ECMWF ocean reanalysis system ORAS4. Quart. J. Roy. Meteor. Soc., 139, 1132-1161, https://doi.org/10.1002 qj.2063.

—_, and Coauthors, 2015: The Ocean Reanalyses Intercomparison Project (ORA-IP). J. Oper. Oceanogr., 8 (Suppl.), s80-s97, https://doi.org/10.1080/1755876X.2015.1022329.

Bos, M. S., S. D. P. Williams, I. B. Araújo, and L. Bastos, 2014: The effect of temporal correlated noise on the sea level rate and acceleration uncertainty. Geophys. J. Int., 196, 1423-1430, https://doi.org/10.1093/gji/ggt481.

Boyer, T., S. Levitus, H. Garcia, R. A. Locarnini, C. Stephens, and J. Antonov, 2005: Objective analyses of annual, seasonal, and monthly temperature and salinity for the World Ocean on a $0.25^{\circ}$ grid. Int. J. Climatol., 25, 931-945, https://doi.org/10.1002/ joc. 1173 .

Cabanes, C., and Coauthors, 2013: The CORA dataset: Validation and diagnostics of in-situ ocean temperature and salinity measurements. Ocean Sci., 9, 1-18, https://doi.org/10.5194/ os-9-1-2013

Calafat, F. M., D. P. Chambers, and M. N. Tsimplis, 2012: Mechanisms of decadal sea level variability in the eastern North Atlantic and the Mediterranean Sea. J. Geophys. Res., 117, C09022, https://doi.org/10.1029/2012JC008285.

Carton, J. A., and B. S. Giese, 2008: A reanalysis of ocean climate using Simple Ocean Data Assimilation (SODA) Mon. Wea. Rev., 136, 2999-3017, https://doi.org/10.1175/ 2007MWR1978.1.
Cazenave, A., and W. Llovel, 2010: Contemporary sea level rise. Annu. Rev. Mar. Sci., 2, 145-173, https://doi.org/10.1146/ annurev-marine-120308-081105.

Chambers, D. P., 2006: Observing seasonal steric sea level variations with GRACE and satellite altimetry. J. Geophys. Res., 111, C03010, https://doi.org/10.1029/2005JC002914.

Cheung, A. H., M. E. Mann, B. A. Steinman, L. M. Frankcombe, M. H. England, and S. K. Miller, 2017: Comparison of lowfrequency internal climate variability in CMIP5 models and observations. J. Climate, 30, 4763-4776, https://doi.org/ 10.1175/JCLI-D-16-0712.1.

Church, J. A., and Coauthors, 2010: Ocean temperature and salinity contributions to global and regional sea-level change. Understanding Sea-Level Rise and Variability, J. A. Church et al., Eds., Blackwell Publishing, 143-176.

and Coauthors, 2013a: Sea level change. Climate Change 2013: The Physical Science Basis, T. F. Stocker et al., Eds., Cambridge University Press, 1137-1216, http://www.ipcc.ch/pdf/ assessment-report/ar5/wg1/WG1AR5_Chapter13_FINAL.pdf. D. Monselesan, J. M. Gregory, and B. Marzeion, 2013b: Evaluating the ability of process based models to project sealevel change. Environ. Res. Lett., 8, 014051, https://doi.org/ 10.1088/1748-9326/8/1/014051.

Deser, C., M. A. Alexander, S.-P. Xie, and A. S. Phillips, 2010: Sea surface temperature variability: Patterns and mechanisms. Annu. Rev. Mar. Sci., 2, 115-143, https://doi.org/10.1146/ annurev-marine-120408-151453.

Di Lorenzo, E., and Coauthors, 2008: North Pacific Gyre Oscillation links ocean climate and ecosystem change. Geophys. Res. Lett., 35, L08607, https://doi.org/10.1029/2007GL032838.

Domingues, C. M., J. A. Church, N. J. White, P. J. Gleckler, S. E. Wijffels, P. M. Barker, and J. R. Dunn, 2008: Improved estimates of upper-ocean warming and multi-decadal sea-level rise. Nature, 453, 1090-1093, https://doi.org/10.1038/nature07080.

Enfield, D. B., A. M. Mestas-Nuñez, and P. J. Trimble, 2001: The Atlantic multidecadal oscillation and its relation to rainfall and river flows in the continental U.S. Geophys. Res. Lett., 28 , 2077-2080, https://doi.org/10.1029/2000GL012745.

Frankcombe, L. M., S. McGregor, and M. H. England, 2015: Robustness of the modes of Indo-Pacific sea level variability. Climate Dyn., 45, 1281-1298, https://doi.org/10.1007/ s00382-014-2377-0.

Frankignoul, C., and K. Hasselmann, 1977: Stochastic climate models. Part II: Application to sea-surface temperature anomalies and thermocline variability. Tellus, 29, 289-305, https://doi.org/10.3402/tellusa.v29i4.11362.

Good, S. A., M. J. Martin, and N. A. Rayner, 2013: EN4: Quality controlled ocean temperature and salinity profiles and monthly objective analyses with uncertainty estimates. J. Geophys. Res. Oceans, 118, 6704-6716, https://doi.org/ 10.1002/2013JC009067.

Gouretski, V., and F. Reseghetti, 2010: On depth and temperature biases in bathythermograph data: Development of a new correction scheme based on analysis of a global ocean database. DeepSea Res. I, 57, 812-833, https://doi.org/10.1016/j.dsr.2010.03.011.

Gregory, J. M., and Coauthors, 2013a: Climate models without preindustrial volcanic forcing underestimate historical ocean thermal expansion. Geophys. Res. Lett., 40, 1600-1604, https:// doi.org/10.1002/grl.50339.

and Coauthors, 2013b: Twentieth-century global-mean sea level rise: Is the whole greater than the sum of the parts? J. Climate, 26, 4476-4499, https://doi.org/10.1175/ JCLI-D-12-00319.1. 
Hamlington, B. D., R. R. Leben, and K.-Y. Kim, 2012: Improving sea level reconstructions using non-sea level measurements. J. Geophys. Res., 117, C10025, https://doi.org/10.1029/ 2012JC008277.

Hammami, D., T. S. Lee, T. B. M. J. Ouarda, and J. Lee, 2012: Predictor selection for downscaling GCM data with LASSO. J. Geophys. Res., 117, D17116, https://doi.org/10.1029/ 2012JD017864.

Hamon, M., G. Reverdin, and P.-Y. Le Traon, 2012: Empirical correction of XBT data. J. Atmos. Oceanic Technol., 29, 960973, https://doi.org/10.1175/JTECH-D-11-00129.1.

Han, W., G. A. Meehl, D. Stammer, A. Hu, B. Hamlington, J. Kenigson, H. Palanisamy, and P. Thompson, 2017: Spatial patterns of sea level variability associated with natural internal climate modes. Surv. Geophys., 38, 217-250, https://doi.org/ 10.1007/s10712-016-9386-y.

Hastie, T., R. Tibshirani, and M. Wainwright, 2015: Statistical Learning with Sparsity: The Lasso and Generalizations. Chapman and Hall/CRC, 351 pp.

Hay, C. C., E. Morrow, R. E. Kopp, and J. X. Mitrovica, 2015: Probabilistic reanalysis of twentieth-century sea-level rise. Nature, 517, 481-484, https://doi.org/10.1038/nature14093.

Hebiri, M., and J. Lederer, 2013: How correlations influence LASSO prediction. IEEE Trans. Inf. Theory, 59, 1846-1854, https://doi.org/10.1109/TIT.2012.2227680.

Ishii, M., M. Kimoto, K. Sakamoto, and S.-I. Iwasaki, 2006: Steric sea level changes estimated from historical ocean subsurface temperature and salinity analyses. J. Oceanogr., 62, 155-170, https://doi.org/10.1007/s10872-006-0041-y.

Kennedy, J. J., N. A. Rayner, R. O. Smith, D. E. Parker, and M. Saunby, 2011a: Reassessing biases and other uncertainties in sea surface temperature observations measured in situ since 1850: 1. Measurement and sampling uncertainties. J. Geophys. Res., 116, D14103, https://doi.org/10.1029/2010JD015218.

,,,,---- , and,$- 2011 \mathrm{~b}$ : Reassessing biases and other uncertainties in sea surface temperature observations measured in situ since 1850: 2. Biases and homogenization. J. Geophys. Res., 116, D14104, https://doi.org/10.1029/2010JD015220.

Levitus, S., J. I. Antonov, T. P. Boyer, H. E. Garcia, and R. A. Locarnini, 2005a: EOF analysis of upper ocean heat content, 1956-2003. Geophys. Res. Lett., 32, L18607, https://doi.org/ 10.1029/2005GL023606.

,,,,---- and,$- 2005 \mathrm{~b}$ : Linear trends of zonally averaged thermosteric, halosteric, and total steric sea level for individual ocean basins and the World Ocean, (1955-1959)(1994-1998). Geophys. Res. Lett., 32, L16601, https://doi.org/ 10.1029/2005GL023761.

— mosteric sea level change (0-2000 m), 1955-2010. Geophys. Res. Lett., 39, L10603, https://doi.org/10.1029/2012GL051106.

Ljung, G. M., and G. E. P. Box, 1978: On a measure of lack of fit in time series models. Biometrika, 65, 297-303, https://doi.org/ 10.1093/biomet/65.2.297.

Llovel, W., J. K. Willis, F. W. Landerer, and I. Fukumori, 2014: Deep-ocean contribution to sea level and energy budget not detectable over the past decade. Nat. Climate Change, 4, 10311035, https://doi.org/10.1038/nclimate2387.

Locarnini, R. A., and Coauthors, 2013: Temperature. Vol. 1, World Ocean Atlas 2013, NOAA Atlas NESDIS 73, 40 pp.

Lombard, A., A. Cazenave, P.-Y. Le Traon, and M. Ishii, 2005: Contribution of thermal expansion to present-day sea-level change revisited. Global Planet. Change, 47, 1-16, https:/doi.org/ 10.1016/j.gloplacha.2004.11.016.
Luthcke, S. B., T. J. Sabaka, B. D. Loomis, A. A. Arendt, J. J. McCarthy, and J. Camp, 2013: Antarctica, Greenland and Gulf of Alaska land-ice evolution from an iterated GRACE global mascon solution. J. Glaciol., 59, 613-631, https://doi.org/ 10.3189/2013JoG12J147.

Madec, G., 2008: NEMO reference manual, ocean dynamic component: NEMO-OPA. Institut Pierre Simon Laplace Note du Pôle de Modélisation Tech. Rep. 27, 386 pp.

Mantua, N. J., and S. R. Hare, 2002: The Pacific decadal oscillation. J. Oceanogr., 58, 35-44, https://doi.org/10.1023/A: 1015820616384

, _ , Y. Zhang, J. M. Wallace, and R. C. Francis, 1997: A Pacific interdecadal climate oscillation with impacts on salmon production. Bull. Amer. Meteor. Soc., 78, 1069-1079, https:// doi.org/10.1175/1520-0477(1997)078<1069:APICOW >2.0.CO;2.

McDougall, T. J., and P. M. Barker, 2011: Getting started with TEOS-10 and the Gibbs Seawater (GSW) oceanographic toolbox. SCOR/IAPSO WG127, $28 \mathrm{pp}$.

Meyssignac, B., and A. Cazenave, 2012: Sea level: A review of present-day and recent-past changes and variability. J. Geodyn., 58, 96-109, https://doi.org/10.1016/j.jog.2012.03.005.

- - D. Salas y Melia, M. Becker, W. Llovel, and A. Cazenave, 2012: Tropical Pacific spatial trend patterns in observed sea level: Internal variability and/or anthropogenic signature? Climate Past, 8, 787-802, https://doi.org/10.5194/ cp-8-787-2012.

Millero, F. J., 2010: History of the equation of state of seawater. Oceanography, 23 (3), 18-33, https://doi.org/10.5670/ oceanog.2010.21.

Newman, M., and Coauthors, 2016: The Pacific decadal oscillation, revisited. J. Climate, 29, 4399-4427, https://doi.org/10.1175/ JCLI-D-15-0508.1.

Nidheesh, A. G., M. Lengaigne, J. Vialard, A. S. Unnikrishnan, and H. Dayan, 2013: Decadal and long-term sea level variability in the tropical Indo-Pacific Ocean. Climate Dyn., 41, 381-402, https://doi.org/10.1007/s00382-012-1463-4.

,,,--- T. Izumo, A. S. Unnikrishnan, and C. Cassou, 2017: Influence of ENSO on the Pacific decadal oscillation in CMIP models. Climate Dyn., 49, 3309-3326, https://doi.org/ 10.1007/s00382-016-3514-8.

Palanisamy, H., A. Cazenave, T. Delcroix, and B. Meyssignac, 2015: Spatial trend patterns in the Pacific Ocean sea level during the altimetry era: The contribution of thermocline depth change and internal climate variability. Ocean Dyn., $\mathbf{6 5}$, 341-356, https://doi.org/10.1007/s10236-014-0805-7.

Pfeffer, J., and P. Allemand, 2016: The key role of vertical land motions in coastal sea level variations: A global synthesis of multisatellite altimetry, tide gauge data and GPS measurements. Earth Planet. Sci. Lett., 439, 39-47, https://doi.org/ 10.1016/j.epsl.2016.01.027.

Piecuch, C. G., and R. M. Ponte, 2011: Mechanisms of interannual steric sea level variability. Geophys. Res. Lett., 38, L15605, https://doi.org/10.1029/2011GL048440.

Purkey, S. G., G. C. Johnson, and D. P. Chambers, 2014: Relative contributions of ocean mass and deep steric changes to sea level rise between 1993 and 2013. J. Geophys. Res. Oceans, 119, 7509-7522, https://doi.org/10.1002/2014JC010180.

Rasmusson, E. M., and J. M. Wallace, 1983: Meteorological aspects of the El Niño/Southern Oscillation. Science, 222, 1195-1202, https://doi.org/10.1126/science.222.4629.1195.

Ray, R. D., 1998: Spectral analysis of highly aliased sea-level signals. J. Geophys. Res., 103, 24991-25003, https://doi.org/ 10.1029/98JC02545. 
Roberts, C. D., D. Calvert, N. Dunstone, L. Hermanson, M. D. Palmer, and D. Smith, 2016: On the drivers and predictability of seasonal-to-interannual variations in regional sea level. J. Climate, 29, 7565-7585, https://doi.org/10.1175/ JCLI-D-15-0886.1.

Roemmich, D., and Coauthors, 2009: The Argo Program: Observing the global ocean with profiling floats. Oceanography, 22 (2), 34-43, https://doi.org/10.5670/oceanog.2009.36.

Saji, N. H., and T. Yamagata, 2003: Possible impacts of Indian Ocean dipole mode events on global climate. Climate Res., $\mathbf{2 5}$, 151-169, https://doi.org/10.3354/cr025151.

— B. B. N. Goswami, P. N. Vinayachandran, and T. Yamagata, 1999: A dipole mode in the tropical Indian Ocean. Nature, 401, 360-363, https://doi.org/10.1038/43854.

Santer, B. D., T. M. L. Wigley, J. S. Boyle, D. J. Gaffen, J. J. Hnilo, D. Nychka, D. E. Parker, and K. E. Taylor, 2000: Statistical significance of trends and trend differences in layer-average atmospheric temperature time series. J. Geophys. Res., 105, 7337-7356, https://doi.org/10.1029/1999JD901105.

Stammer, D., 1997: Steric and wind-induced changes in TOPEX/ POSEIDON large-scale sea surface topography observations. J. Geophys. Res., 102, 20 987-21 009, https://doi.org/10.1029/ 97JC01475.

_, A. Cazenave, R. M. Ponte, and M. E. Tamisiea, 2013: Causes for contemporary regional sea level changes. Annu. Rev. Mar. Sci., 5, 21-46, https://doi.org/10.1146/annurev-marine-121211-172406.

Storto, A., and Coauthors, 2017: Steric sea level variability (19932010) in an ensemble of ocean reanalyses and objective analyses. Climate Dyn., 49, 709-729, https://doi.org/10.1007/ s00382-015-2554-9.

Tibshirani, R., 1996: Regression shrinkage and selection via the LASSO. J. Roy. Stat. Soc., 58B, 267-288.

Toiviainen, P., V. Alluri, E. Brattico, M. Wallentin, and P. Vuust, 2014: Capturing the musical brain with LASSO: Dynamic decoding of musical features from fMRI data. NeuroImage, 88, 170-180, https://doi.org/10.1016/j.neuroimage.2013.11.017.

Uppala, S. M., and Coauthors, 2005: The ERA-40 Re-Analysis. Quart. J. Roy. Meteor. Soc., 131, 2961-3012, https://doi.org/ 10.1256/qj.04.176.
Usai, M. G., M. E. Goddard, and B. J. Hayes, 2009: LASSO with cross-validation for genomic selection. Genet. Res., 91, 427436, https://doi.org/10.1017/S0016672309990334.

Volkov, D. L., S.-K. Lee, F. W. Landerer, and R. Lumpkin, 2017: Decade-long deep-ocean warming detected in the subtropical South Pacific. Geophys. Res. Lett., 44, 927-936, https://doi.org/ 10.1002/2016GL071661.

Wahr, J., R. S. Nerem, and S. V. Bettadpur, 2015: The pole tide and its effect on GRACE time-variable gravity measurements: Implications for estimates of surface mass variations. J. Geophys. Res. Solid Earth, 120, 4597-4615, https://doi.org/ 10.1002/2015JB011986.

White, N. J., and Coauthors, 2014: Australian sea levels-Trends, regional variability and influencing factors. Earth-Sci. Rev., 136, 155-174, https://doi.org/10.1016/j.earscirev.2014.05.011.

Wolter, K., 1987: The Southern Oscillation in surface circulation and climate over the tropical Atlantic, Eastern Pacific, and Indian Oceans as captured by cluster analysis. J. Climate Appl. Meteor., 26, 540-558, https://doi.org/10.1175/ 1520-0450(1987)026<0540:TSOISC $>2.0$.CO;2.

, and M. S. Timlin, 1993: Monitoring ENSO in COADS with a seasonally adjusted principal component index. Proc. 17th Climate Diagnostics Workshop, Norman, OK, NOAA/NMC/ CAC, 52-57.

— 1871 as diagnosed in an extended multivariate ENSO index (MEI. ext). Int. J. Climatol., 31, 1074-1087, https://doi.org/10.1002/joc.2336.

Yang, C., S. Masina, and A. Storto, 2017: Historical ocean reanalyses (1900-2010) using different data assimilation strategies. Quart. J. Roy. Meteor. Soc., 143, 479-493, https://doi.org/10.1002/qj.2936.

Yang, J., Q. Liu, S.-P. Xie, Z. Liu, and L. Wu, 2007: Impact of the Indian Ocean SST basin mode on the Asian summer monsoon. Geophys. Res. Lett., 34, L02708, https://doi.org/10.1029/ 2006GL028571.

Zhang, X., and J. A. Church, 2012: Sea level trends, interannual and decadal variability in the Pacific Ocean. Geophys. Res. Lett., 39, L21701, https://doi.org/10.1029/2012GL053240.

Zweng, M., and Coauthors, 2013: Salinity. Vol. 2, World Ocean Atlas 2013, NOAA Atlas NESDIS 74, 49 pp. 